\title{
Rethinking Therapeutic Misconception in Biobanking - Ambivalence Between Research and Treatment
}

\author{
Aaro Tupasela \\ Public Health, University of Copenhagen, Denmark/ aatu@sund.ku.dk \\ Karoliina Snell \\ Department of Social Research, University of Helsinki, Finland \\ Jose A. Cañada \\ Department of Social Research, University of Helsinki, Finland
}

Centre for Medical Science and Technology Studies, Section for Health Services Research, Department of

\begin{abstract}
Some authors have noted that in biobank research participants may be guided by what is called therapeutic misconception, whereby participants attribute therapeutic intent to research procedures. This article argues that the notion of therapeutic misconception is increasingly less justified when evaluating biobanks. We present four examples taken from recent developments in biobanking to argue why the notion of therapeutic misconception is problematic in that biobanking practices are increasingly seeking to bridge research and treatment in different ways. In this article we explore examples where the boundary between research and treatment become increasingly blurred, as well as the contextual significance of healthcare systems and their prevailing ideologies in healthcare management. We argue that biobanking practices are challenging the use value, as well as the philosophical and ethical underpinnings for the need to separate research and treatment, and thus the notion of therapeutic misconception in the first place. We call this tension between research and treatment ambivalent research advancement to highlight the difficulties that various actors have in managing such shifts within the healthcare-research systems.
\end{abstract}

Keywords: biobanks, therapeutic misconception, treatment, individual research results (IRR), incidental findings (IF), healthcare policy.

\section{Introduction}

A number of recent commentators have noted that in biobank research participants may be guided by what is called therapeutic misconcep- tion, whereby participants attribute therapeutic intent to research procedures (Zawati \& Knoppers, 2012; Forsberg et al. 2009; Appelbaum et al., 1982). 
In participating in research, some participants may indeed feel that they are receiving some type of treatment or therapy despite the fact that they are given an informed consent form to read and sign, which has stated that this is not the case. A number of studies have shown how the informed consent procedure is problematic, especially concerning biobanking studies (Skolbekken et al., 2005; Hoeyer, 2003, 2008; Hoeyer \& Hogle, 2014). Other studies, however, have demonstrated that people are motivated by participating and contributing to a common good and do not expect direct benefits for themselves - even though they would prefer the benefits (Snell et al., 2012; Pellegrini et al., 2014; Wallace \& Kent, 2011). Furthermore, in a number of studies where tissue samples, as well as health and lifestyle information is gathered, such as longitudinal cohort studies, people do receive immediate feedback and information on their health. These include blood pressure, body fat levels, sugar levels and other pertinent health related information, which is often experienced as care. The process of participation in itself is often seen as an opportunity to interact and discuss personal health related matters with healthcare professionals, which further compounds the notion that participants are receiving health related treatment, as opposed to participating in research (Nobile et al., 2013). Some have argued that it is not a misconception to assume one will receive good care during research, but it is a misconception if one believes that the purpose of the research is to provide treatment rather than conduct research (Henderson et al., 2007; National Bioethics Advisory Commission, 2001). It is clear, however, that people's expectations about research are not straightforward as is not the relationship between research and care.

The interest to maintain a distinction between research and treatment and the role of the research subject vs patient has been a longstanding issue within medical ethics. The roots of this lie in important policy documents, such as the Belmont report (1979), which sought to protect human research subjects from unwittingly becoming enrolled within research projects, but also to ensure that research participants are able to make an informed decision (Halverson and Friedman Ross, 2012). The dichotomy between research and treatment has been well established and rigorously defended from a philosophical and ethical perspective, whereby the practice of maintaining this distinction has been meant to protect patients from possible harms, which may come about through enrolling in research without being fully aware of the consequences.

The debate of separation of research and treatment has, however, had a somewhat different tone in relation to biobanking. Commentators have sought to point out how biobank research differs fundamentally from other types of clinical research, such as drug trials, in that it does not require further intervention into the human body (except for the drawing of blood for cohort studies, for example) (Deschênes et al., 2001; Hansson et al., 2006; Cambon-Thomsen et al., 2007). Some have also suggested that biobank research ought to be comparable to registry-based research in that samples drawn from patients are comparable to any other type of data collected on the patient (Aromaa et al., 2002). Such positions have sought to argue that biobankers can withdraw from an ethical debate relating to therapeutic misconception, whereas in fact biobanking is increasingly collapsing research and treatment in novel ways. This collapse in the distinction between research and treatment is giving rise to novel forms of responsibility and ambiguity to various practitioners, such as physicians, biobankers, as well as laboratory technicians (cf. Wadmann \& Hoeyer, 2014). Indeed, there are increasing examples of the difficulties that states, for example, have in trying to define the scope of responsibility between, patients, research subjects, physicians, and biobankers when it comes to managing findings (Tupasela, 2015; Tupasela \& Liede, 2016).

As such, the notion of therapeutic misconception, which is used to describe scenarios and situations where patients may become unwittingly research subjects, also falls under question as a useful theoretical and analytical tool for understanding the ways in which research and treatment are changing with relation to biobanking. As Dresser (2002: 276) has noted, "intentionally or inadvertently, they [researchers] encourage participants' therapeutic expectations in numerous ways. Some encouragement comes from the consent forms that are supposed 
to explain how research participation will differ from ordinary patient care." For new biobanking practices, however, the situation is further compounded by the very context in which the distinctions between research and treatment are becoming increasingly blurred.

This article contextualizes this discussion within a broader framework where it is increasingly difficult to maintain a useful distinction between research and treatment in relation to the biomedical collection and use of tissue samples and data, or biobanking. We provide four international examples, which highlight the ways in which research and treatment are encroaching and blurring this supposed boundary as a result of new ways of studying disease and combining information gained from tissue sample collections and other pertinent medical information. Much like the artificiality of the boundary between basic and applied research that has been criticised by Stokes (1997), we wish to suggest that the distinction between research and treatment is increasingly problematic and fails to reflect the rapid changes taking place in the research and treatment interface. These changes are taking place in both the public and private sector, and reflect a broader systemic shift in the way research and treatment are being organized in relation to biobanking.

The Nordic countries, in particular, have been able to capitalize on their ability to collect and compare information gained from tissues with registry data. Some have gone as far as to claim that the whole population serves as a type of cohort in some cases (Frank, 2000). We thus seek to question whether the notion of therapeutic misconception is useful anymore in relation to developments in biobanking since biobanking is seeking to collapse the two together. This also has important consequences in relation to a re-definition and redistribution of responsibilities among the actors. This approach is based on the understanding that research fields, which rely on biobanks for example, are not just governed from above. Instead, we would like to suggest that research drawing on biobanking is also giving rise to novel forms of medical intervention and treatment where the relationship between treatment and research is by design iterative and reflexive, as opposed to distinct and separate. The rapid development of biobanking during the past decade has brought with it a number of challenges for both the medical research system, as well as the delivery of healthcare in general. At the heart of this challenge lies a progressive ideology regarding the way in which medical research is conducted, as well as the ways in which illness is detected and treated.

In the following, we will seek to contextualize how we see developments in biobanking as problematizing the very notion of therapeutic misconception through four examples. We argue that rather than seeking to continuously uphold the dichotomy of research and treatment, one should begin to recognize the myriad of ways in which biobanking practices, as well as some policies, are giving rise to novel ways of treating people, and developing ways in which practices can be accounted for and recognized in legal and ethical discourse. Although some of these approaches are problematic, we nonetheless consider it an important policy step to try and account for this change as opposed to fight it.

\section{Methods and Materials}

This research is based on a two-year project, which sought to understand the forms and styles of engagement that various biobanks undertook in six countries: USA, Canada, UK, Spain, Finland and Iceland. Although the main remit of our research was to focus on engagement strategies of biobanks in these different countries, our data also produced results on the ways in which biobanks come about, as well as the multifaceted contexts in which they operate. This broad variation provides a contrast to the general international policies and guidelines regarding the separation of research and treatment. It became evident during our research that a number of biobanking constellations were in fact blurring the boundary between research and treatment, whereby it became increasingly difficult for actors to justify the existing dichotomy. In conducting our research, we did 26 interviews with relevant personnel from different biobanks, as well as biobank networks in six different countries. We also conducted interviews with policy makers and regulators in the various countries to develop 
a broader picture of the nature of biobanking in the various countries. Our interviews were based on a semi-structured interview framework where we focused on specific themes relating to sustainability and engagement practices. In this article, we focus on examples whereby we highlight and problematize some of the issues that are faced in biobanking today in relation to maintaining a distinction between research and treatment.

In examining our data, we came across situations in which the boundary between research and treatment was blurred and the usefulness of the notion of therapeutic misconception was becoming an increasingly problematic conceptual tool to understanding the role of the patient in the research system vs receiving treatment. Here we present four examples that are drawn from three countries; two from Finland, one from the UK and one from the USA. Although one may say, that these cases represent 'special' cases, and are not representative, we argue that they are indicative of the direction in which research, using biobanks, is increasingly moving in. The possibilities that are becoming available to researchers in such new configurations are substantially more competitive and productive than conventional research settings. We see an increasing pressure for research systems to move towards constellations where there is increasing iteration between the research and clinical settings.

\section{Biobanks and Ambivalent Research Settings}

A central problem related to the therapeutic misconception relates to the ways in which information derived from biobank research is, or is not, communicated with research subjects, as well as the expectations that research subjects may have in relation to participation in research (Eriksson, 2004). Miller et al. (2008) have noted that there has emerged a new ethical imperative whereby researchers are increasingly expected to communicate the results of their research to participants. Similarly, Smith and Aufox (2013: 7) have noted that "new paradigms are currently needed for understanding and relaying research results made possible by current and future genetic technologies as they evolve." On a more general level, the changes taking place in the biomedical field reflect a broader shift in the way data is collected and used. As Rodriguez (2013: 2) argues, society is becoming increasingly "data rich and dependent." As a consequence of this proliferation and dependence on different types of data, biobanking applications and uses are having profound effects on the way medical research and treatment is being organized and delivered.

Two aspects, in particular, have played an important role on the discussions related to therapeutic misconception; the return of incidental findings (IF) and the return of individual research results (IRR). A number of recent studies have identified inconsistencies between international norms and guidelines on the return of IRR and $\mathrm{IF}$, and the practices associated with biobanking. The studies note that there is no international consensus on the ways in which information from biobanking research should be returned to individuals (Wolf, 2013; Zawati \& Knoppers, 2012; Bledsoe et al., 2013; Forsberg et al., 2009). Many of these studies have called for international guidelines regarding the return of IRR and IF (Zawati \& Knoppers, 2012). The ambiguities associated with whether or not information ought to be shared with research participants highlights the tenuous relationship that biobanking is producing in relation to its research population in general. As biobanks continue to develop into more sophisticated systems for the collection and analysis of information, so too develops their ability to speak back to participants and society in general in relation to the health risks that individuals and populations may have. We call this development ambivalent research advancement in that increasingly actors involved and surrounding biobanking - researchers, policy makers, ethics committees, etc. - inhabit an ambivalent position in relation to how information ought to be managed and disseminated. In these new constellations between research and treatment biobanks serve as intermediaries through which the traditional boundary between research and treatment is becoming increasingly blurred. Biobanks are hailed as important sources of material and data for research, but increasingly the ability of researchers and doctors to glean immediate benefit for patients and research subjects is 
becoming clearer. In this sense, we argue that the advancements in research are also producing a type of ambivalence in that the notion of therapeutic misconception plays an important part in the research ethos, whereby researchers and doctors still try to maintain a boundary, albeit false in many cases, between research and treatment.

In part, it is understandable that research participants may be guided by the therapeutic misconception given that there appears to be a great degree of professional ambiguity, as well with regards to the ways in which genetic research results ought to be managed. Pullman and Hodgkinson (2006), for example, have argued that although there is increasing literature regarding the duty of physicians to warn at risk relatives in the context of genetic testing (cf. Tupasela, 2006; Offit et al., 2004), not enough has been discussed in relation to the management of genetic research results. More recently, the American College of Medical Genetics (2013) published a recommendation on reporting on clinical exome and genome sequencing results of 24 conditions. The report was met with criticism in that some felt that it went too far in terms of setting a requirement for labs and doctors to report on incidental findings. These examples regarding return of individual research results and incidental findings highlight the ways in which participation in biobank research is raising a number of concerns, which even professional groups are unable to address in a clear manner since biobanks play an important role in practices related to genetic research. The patchwork of practices related to reporting has contributed, we would argue, to an ambiguity in which the delineation between research and clinical practice is often difficult to ascertain.

Zawati \& Knoppers (2012) have recently noted that "it is important to encourage endeavours that aim to provide a clear set of definitions related to the return of IRRs and IFs at the international level." This, according to them, will allow for much needed consistency in international norms and will reduce ambiguity and contradictions." (Zawati \& Knoppers, 2012: 488) Although their approach is commendable, we believe that it misses a crucial perspective related to some more recent trends in biobanking research and treatment, namely that biobanking practices and the forms of research that are aligned with them are giving rise to novel forms of intervention where the distinction between research and treatment is increasingly blurred. We argue that seeking to set standards and guidelines before we know and see the ways in which biobanking can change the ways in which research is done and healthcare delivered might lead to more problems than what is actually solved. A number of examples can be drawn on where the iterative process between research and treatment is becoming increasingly intermingled.

There is also a problem with the notion of therapeutic misconception in relation to the development and philosophical assumptions enshrined within new personalized medical technologies (European Commission, 2013), as well as health care technology management systems. This is because much of new personalized medicine being developed is founded on the idea, to some extent, of an ongoing iteration between the patient and the research where biobanks play a critical role (Yuille et al., 2008; Riegman et al., 2008; EU workshop, 2003; OECD, 2001). In this sense, the separation of research and treatment is being brought together as a means of overcoming methodological and data problems in biomedical research. In order to develop more accurate data on and for the patient or patient populations, the patient and the research population need to be brought in closer within the 'fold' of research practices.

Furthermore, with the rise of personalized medicine as a major policy program for most Western countries there is an increased interest in the acceleration of the translation of knowledge gained from biomedical research into treatment. Biobanks are seen as a critical element in this process in that they will provide the basis from which actionable biomarkers can be identified for selecting the right drug targets, as well as the development of new drugs in the first place (Hewitt, 2011). Some commentators have noted that biobanking needs to focus increasingly on being evidence based and geared towards customer satisfaction in order to ensure long-term sustainability (Simeon-Dubach and Watson, 2014). Together these factors are influencing the ways in which research and treatment are configured, and subsequently to the development of therapeutic 
misconceptions among biobanking research subjects.

In the following we will discuss four examples which derive from policy and legal changes, as well as practice-based contexts, which provide concrete instances where the distinction between research and clinical care are becoming increasingly blurred. We believe that these examples are indicative of an increased tension between research and treatment involving biobanks. From these arguments, we seek to criticize the usefulness of therapeutic misconception as a useful category through which to critique biobanking practices. We argue that biobanking is increasingly transcending the boundary, which has been enshrined within medical research ethics.

\section{The Finnish Biobank Act}

Our first example regarding the blurring distinction between research and treatment comes from a recent development in Finland regarding biobanking. Finland is a small Nordic country that has a long tradition of registry-based research, as well as collecting tissue samples for research (Tupasela, 2004). The Nordic countries have in general collected and maintained numerous registries and collections related to human health that can be cross-referenced using a unified social security number system In this sense, the Nordic countries maintain somewhat of a unique position internationally with regard to their collections. A number of these countries have also been early movers in terms of setting up major biobanking initiatives within their borders. The Norwegian HUNT Biobank, for example, has a collection of over 250000 DNA samples, whose physical management and analysis is highly automated (HUNT Biobank, 2015).

In a similar vein, Finland has also been seeking to develop and bolster its use of exiting tissue sample collections and related registry and health information. In doing so, it has implemented a new Biobank Act, which according to Soini (2013) is the only one of its kind in the world. The Act brings under one legal instrument all biobanks, including clinical, research, public or private. Besides its broad scope, the novelty of the Biobank Act lies in its position regarding the right of participants to gain access and informa- tion regarding their samples, which appears to go against international trends regarding return of IRR (Tupasela, 2015). Burke et al. (2014: 107) have, for example, argued that "the weight of bioethical and researcher opinion argues against granting research subjects an unrestricted right to demand return of individual research results." In Finland, however, the broadening of the ability of researchers to access samples and health related data has been met with increased responsibility to provide information on actionable findings if a participant requests it.

Against this backdrop, it is rather surprising that in its Biobank Act (688/2012), the Finnish legislature went against the international norms and guidelines by including the following section in the Act:

\footnotetext{
A registered individual has the right to receive, upon request, information concerning his or her health as determined based on a sample. When providing information determined based on the sample, the person must be provided with an opportunity to receive an account of the significance of the information. A fee may be charged for clarifying the significance of the information that, at maximum, corresponds to the expenses incurred by providing the clarification. (Biobank Act 688/2012 Section 39.)
}

From a practical perspective, this would mean that if a person were to know that a sample from them has been collected, then they would have a right to know if that samples has been used in research, as well as what types of research it has been used in. Furthermore, they would also have the right to know - at their own expense - what the significance of the research findings have in relation to their own sample. This position has been further clarified to mean that biobanks need only report on significant and actionable results if any are found in the studies. This is the first time in which, at a national level, biobanks have been required to provide people whose samples have been used with an explanation of the significance of the existing findings in relation to their sample if it is actionable. This move fundamentally alters the nature of research and the dynamic of participation in that with the new Act, research partici- 
pants can expect that they have a legal right to request information if it is actionable.

This requirement, however, is not without its problems. As one administrator noted, the law raises a number of problems in relation to the operation of biobanks and the delivery of healthcare in society:

You can think of it by imagining that the younger, healthier and more active you are, then the more information they can get during their life from that biobank. They can go to the biobank and get all the information that they want, they can ask. These possibilities have been made available to them through the broad consent. But if they are active in getting this information then there are also going to be problems, if they suddenly want to know all their risks if the sample has been used for some research study and then returned back to the biobank. (Interview with hospital administrator, Fl 2013.)

The interview excerpt highlights a new type of concern for Nordic countries in relation to equality in relation to healthcare access and information, whereby younger generations may be more active in seeking information on their health based on samples being used in biobank research.

Another interviewee was more critical in relation to the practical implications that it had for biobanks and the people working in them:

But now it is in the law that people should get all of their results - it is a catastrophic passage! We don't want to attract anyone to participate in that way, because it is enormously laborious to explain to them what there has been found. (Interview with biobank manager, FI 2013.)

This legislative requirement places a heavy burden on the biobank to develop an infrastructure that would be able to manage research subject requests on a practical level. To our knowledge, the biobanks that have been set up thus far in Finland have not been faced with such a situation. Most participants are not aware of either the new law or the fact that their samples could be used for further research, but it is inevitable that someone will sometime in the future request information regarding the use of their sample, the research findings, as well as a translation of the significance of those findings to themselves.

We consider this to be the first substantiation, at the national level, and codified in law, whereby individuals whose samples have been stored in a biobank have the right to gain information regarding their samples and the research that has been done on it. This legal move can be seen as a major challenge to the traditional dichotomy between research and clinical care. Furthermore, it raises serious questions as to the functionality of the notion of therapeutic misconception since the law seeks to provide a loophole of types for research participants to request actionable health information based on research conducted on their tissue sample.

\section{Hospital-based Biobank Research}

The second example we draw on comes from the changing role that hospitals are embracing in relation to the, often large, clinical tissue sample collections, as well as health records that they maintain. During the past decade, the proliferation of biobanks around the world has been significant. The range and scope of newly formed biobanks is also quite broad. One new type of biobank operation is that which is nested in existing hospital systems whereby either old diagnostic collections are re-purposed into new biobanking facilities, new collections are begun or a combination of these two models is adopted (Wilson et al., 2014). Some institutions have stored or archived tissue samples for more than 100 years (Eisemann \& Haga, 1999; Strong, 2000) and it is becoming an important asset, which hospitals can draw on for developing treatments and studying disease in the population. Unlike population cohort studies, which capture a random sample of the population, large hospital systems will have a different picture of the health and disease burden of the local population, as well as a different capacity to react to new findings. In this sense, hospital-based biobanks inhabit a unique place in the healthcare-research nexus. This is particularly so in the Nordic countries where the hospital and healthcare system is largely a publically funded system. Although private medical treatment is available, most serious illnesses and demand- 
ing procedures will be taken care of in the public healthcare sector.

One example of the re-purposing of diagnostic sample collections, which we studied in our research is the Auria Biobank ${ }^{1}$, which became the first clinical biobank established in Finland. The biobank was established by the University of Turku and the hospital districts of Southwest Finland, Satakunta, and Vaasa at the beginning of 2014. The re-purposed biobank obtained a permit from the National Supervisory Authority for Welfare and Health (Valvira) to set up a biobank into which the diagnostic collections from these hospital collections could be transferred. Most of the samples in the collection (about $80 \%$ ) are samples from cancer patients, but the research of the biobank will also focus on diabetes and cardiovascular diseases.

In its implementation, however, the use of clinical samples and related health information the question related to therapeutic misconception becomes increasingly challenging for hospitals to manage since entering the hospital for diagnosis and treatment will also entail becoming entered within the hospital biobank system. Although patients receive an informed consent form before coming to the hospital in which they can choose whether their samples will be entered into the biobank, the case is indicative of the ways in which hospitals are increasingly embedding biobank research infrastructures within their healthcare systems. It also raises a number of challenges in relation to the return of IRR and IF as well. In implementing the re-purposing of clinical samples, the hospital is also creating a research environment where the distance between patient samples and information and the patient becomes increasingly blurred. In a number of our interviews in Finland this issue was discussed. The idea is to "capture all incomers" which means that when patients are called for an elective procedure at the hospital they are sent the invitation along with a consent form so that samples can be entered into the biobank. Once they have consented, every time they come to have a procedure done or a test, an extra sample may be collected and entered into the biobank. Samples are collected or accrued in one of two ways: they are either collected through the lab, which is conducting a test on a patient and the lab screen also includes a request to have a sample collected for the biobank (this may include extraction of plasma or serum etc.). The second route into the biobank is through the operating room where they can get different biopsies from patients.

The integration of everyday hospital routines related to testing and medical procedures to include collection and storage activities is central to the blurring of the boundary between research and treatment in everyday medical practice. In one interview where we were discussing hospital biobanks and the re-use of existing clinical samples, a hospital administrator noted that:

\footnotetext{
...it would mean that a citizen would not know that they are the object of research, if we were only studying their medical records without their consent, but with a permit from the authorities.

(...) in a way it would be more of a survey research - despite the object being a group of patients - where one would not be doing medical research where you would not need to physically interact with the patient, but rather using their information to study them. (Interview with hospital administrator, FI 2013.)
}

The interview highlighted the way in which the role of the patient vs research subject becomes increasingly complex in relation to the double role that begins to emerge. Hospitals are trying to define the boundaries between whether the information and samples they have from patients ought to be managed as information or samples, and whether their patients are patients or research subjects. We see this as an example of ambivalent research advancement, where institutions are seeking to re-define the boundaries and definitions of what it means to be a patient and a research subject within the hospital system. Furthermore, the interview highlights the way in which tissue samples are conceptualized as a form of information to which other criteria for access such as research access to survey data - could be applied in contrast to medical research permits, which usually assume some form of medical intervention (such as drawing blood). In Finland, this approach is not new in relation to biobanks, but rather has been presented earlier whereby tissue samples have been compared to any other type 
of survey or statistical data on populations to which a different set of re-use criteria should be applied in relation to medical research (Aromaa et al., 2002).

Hospital managers are increasingly grappling with the difficulties and challenges of redefinitions of their patient populations and the samples and information that they manage, as well as the storage policies they ought to develop (NørgaardPedersen \& Hougaard, 2007). Current policies and guidelines are not clear as to what the status of patients is with regard to their samples and data. As Douglas et al. (2012) have noted in relation to the secondary use of dried blood spots there is increasing pressure to find uses to existing collections to make them more productive. At the same time, there emerges an ambiguity as to the re-definition of patients as research subjects within the healthcare system and the ways in which information and samples on patients ought to be defined and managed.

\section{UK Biobank Imaging Study}

The third example regarding the difficulties of maintaining a distinction between research and clinical care and the challenge it poses to the notion of therapeutic misconception comes from the UK. The UK Biobank is a major collaborative undertaking, which recruited half a million participants aged between 40-69 years from 2006 to 2010 (Wallace, 2005). The people were recruited from across the country to take part in this project through general practitioners. One of the cornerstones of the UK Biobank project has been that those people participating in the study by providing tissue samples, as well as health and lifestyle information, will not receive any personal research results or incidental findings (Barbour, 2003).

Recently, however, the UK Biobank and its associated Ethics and Governance Council have had to make an exception to this rule with regard to the commencement of an imaging study that they are undertaking. The study requires a body scan (MRI) which measures accurately body fat and tissue composition, which will be analyzed in relation to other markers and lifestyle and health information. According to UK Biobank:
The imaging study will involve magnetic resonance imaging of the brain, heart and abdomen, low power X-ray imaging of bones and joints and ultrasound of neck arteries. The feasibility phase is scheduled to start in 2014 in a dedicated UK Biobank imaging facility at its Coordinating Centre in Cheadle, near Stockport. (UK Biobank, 2014.)

The problem that has arisen with regard to the imaging study is that the radiologists who conduct the imaging will be able to make other pertinent diagnoses based on the scans and x-rays. Due to their professional ethical guidelines, however, those doctors are required to inform patients of any life threatening or serious conditions that may be identified through the imaging. As a result, the UK Biobank has had to undertake a review of its policies, as well as conduct a study regarding IF and return of IRRs.

UK Biobank is working with social scientists and health economists to gain a better understanding of the risks and benefits associated with providing feedback of potentially serious incidental findings to UK Biobank participants during the imaging pilot study. In some cases, these incidental findings can have serious health implications; in others, the medical implications are less clear, and many potentially serious findings may - after further investigation or the passage of time - turn out not to be of concern after all. The impact that feedback of information about potentially serious incidental findings has on participants has not been well researched. This work is important because there is currently no consensus in the research community on which (if any) incidental findings should be fed back and the best methods for doing this. (UK Biobank, 2015.)

The need to re-asses the UK Biobank policy on IF as it relates to the imaging study is an example of the difficulty that some biobanks face in terms of maintaining the distinction between research and clinical care. The case of the UK Biobank imaging study suggests that even the most determined attempts to maintain this distinction may fail due to the innovative possibilities that biobanking research is allowing in relation to the combination of a multitude of different research approaches. In some cases, however, these approaches introduce different criteria of care and treatment with regard 
to the patient population, whereby different ethical and legal standards come into conflict with those which the biobank has sought to follow.

Given that hospitals are increasingly setting up biobanks as part of their routine sample and data collecting processes there also emerges the further problem of defining the limits of responsibilities related to the responsibility of doctors towards their patients. Since organisations representing medical professions, such as the World Medical Association (WMA) are issuing guidelines on biobanking, it is relevant to note that the blurring of the treatment and research boundary within the hospital setting may prove ethically challenging for doctors treating their patients. Furthermore, there is an increasing convergence between the ethical concerns of physicians, nurses, researchers and even lab technicians with regard to emerging biobanking practices. This may arise if important information becomes available through biobank research, but which the treating physicians do not communicate to her patient. An important question, which arises then is the extent of the physicians' responsibility in seeking out information on the patients that they treat, as well as the responsibility of other actors in the biobanking knowledge production process. Limiting physician liability and responsibility may become a necessary move in countries where disputes are settled through costly litigation processes, such as the US.

A further problem relates to the notion that biobanks, in general, are able to control the ways in which their patient populations are studied. Much of the function of informed consent is to control and standardize the ways information gained from samples is managed (i.e. what information is allowed to flow and not flow between the research subjects and the researcher). Yet this case and others like it suggest that the flow of information between various stakeholders is far more porous than what informed consent forms are able to account for (cf. Hoeyer et al., 2015).

The question of professional and ethical guidelines of radiologists, however, raises an even more important question in relation to the role of lab technicians and other research staff who may possess highly specific skills and know-how in relation to making diagnosis based on infor- mation derived from genetic tests and other genome sequence processes. Although a great deal of the work that takes place within laboratories where sequence data is being analyzed remains mundane, there is an increasing ability of lab technicians and other research staff to look at data derived from a single person and identify a possible serious life threatening condition. Although these researchers and lab technicians may not be bound by a code of medical ethics to help patients when possible, some commentators have noted that there is a moral responsibility within the research community to work towards informing individuals of the likelihood of a serious condition (Miller et al., 2008; Fernandez et al., 2003). As the development of whole genome and exome sequencing continues to improve and becomes less expensive, so does the accuracy of predicting more conditions become increasingly likely. The policy of UK Biobank to not provide any feedback to participants, however, has come under question in relation to this particular study and it remains to be seen whether future studies will also have to be evaluated on a case-by-case basis as new findings and possibilities arise.

\section{3andMe Genetic Self-testing}

Our final example relates to the American genetics company 23 andMe, which has been providing genetic self-tests that can be ordered over the internet. 23andMe provided consumers with health information on 254 diseases and conditions, information on genealogy, as well as nondisease traits (Zettler et al., 2014). The genetic tests that they provide are an exemplar of a growing field in the biomedical industry known as consumer medicine (Tupasela, 2010) where companies provide analytical services to consumers on various aspects related to their health based on their genetic profile. Recently, however, the Food and Drug Administration (FDA) has ordered the company to halt their operations regarding their self-test services due to the lack of clinical evidence as to the validity of their claims to health benefits (Prainsack, 2014). The case of 23andMe is instructive in relation to the ways in which private companies have sought to capitalize and develop services which provide both medical information regarding one's health (based on a genetic test), as 
well as collect and study data that is provided by customers who have taken the genetic self-test. The service that 23andMe offered would allow for customers to answer a broad range of health and lifestyle related questions which would then be used to further study correlations between disease and single nucleotide polymorphisms (SNPs). The trouble with their method, according to the FDA and critics of 23andMe, was that in many of the cases the correlations on which they were basing their health risk assessments on lacked clinical validity and were thus misleading consumers.

Curnutte and Testa (2012) have argued that direct-to-consumer (DTC) genetic tests are indicative of a conspicuous instance of co-production where genetic knowledge and biological citizenship become articulated around the genetic consumer. We would further argue that what has made the case of 23andMe so significant is not really the issue of whether its tests are able to provide clinical validity in relation to their significance (although that is certainly an important concern), but more importantly the way in which 23andMe has sought to combine genetic-self tests with their own research. Although 23andMe is one of many other companies that have offered such tests to consumers (others include deCodeMe, Pathway Genomics or Interleukin Genetics) what has made 23andMe of interest in relation to our work is the ways in which it seeks to blur the boundary between research and treatment (in this case genetic risk profiling). The FDA's reasoning for forcing 23andMe to stop offering its test had nothing to do with the model it was using to study people, but rather was focused on issues of validity.

The model that 23andMe developed relied on two types of iteration between their customers and the samples that they had provided. First, as new studies became published related to different genes that were implicated with various conditions and disease, 23andMe would update the profiles of its customers to reflect either and increase or decrease in their risk profile. Second, based on the information that the customer provided concerning their own health and lifestyle 23 andMe would conduct its own research into correlations between genes, environment and lifestyle. Again, these results would feed back into the risk profile that the company would calculate for each customer. It is this closeness between a customers' samples and the information that is produced and gleaned from other publically available studies, which has made 23andMe of interest in relation to the notion of therapeutic misconception. The model that they use seeks to be a combination of the two by collapsing the dichotomy between research and treatment (in this case genetic risk profiling).

McGowan et al. (2010: 261) have noted that "early users approach personal genome scanning with both optimism for genomic research and scepticism about the technology's current capabilities." This would seem to suggest that users are very wary of the type of service that they are receiving as well as the context in which it is being conducted. The fusion of genetic analysis and research through questionnaires does not necessarily, therefore, need to be a problem, as may be suggested by the notion of therapeutic misconception. Although arguably the case of genetic-self-testing is unique compared to clinical research conducted in hospitals the issue of combining testing and research in DTC companies does not appear to produce misconceptions. Instead it serves more of a proof of concept that other practitioners may seek to harness in a more clinically valid and useful manner.

Although the risk profiling services offered by 23andMe are no longer allowed by the FDA (in the USA), we argue that the time it took for the FDA to force the company to halt its services, combined with the model that the company developed, is a sign of what we have called ambivalent research advancement in that it challenges the existing and traditional ways of conducting research and it elicits a certain level of uncertainty from regulators as to the appropriate response. Furthermore, it signals the challenges and tensions, which policy makers confront when having to develop guidelines with such novel approaches to research.

\section{Discussion}

A number of recent commentators have noted how the distinction between research and treatment in biobanking is becoming increasingly difficult to delineate (Burke et al., 2014; Wadmann and Hoeyer, 2014; Smith and Aufox, 2013; Pullman and 
Hodgkinson, 2006) and that this may in fact be contributing to what has been termed therapeutic misconception. Zawati and Knoppers (2012) have suggested that international norms ought to be set up to guide the return of individual research results and incidental findings based on biobank research as one way of ameliorating some of these problems arising from this misconception. We argue, however, that attempts to set up international norms and guidelines fail to address the fundamental change that is going on in medical research. The distinction between the two categories (research and treatment) are becoming increasingly blurred, whereby research and treatment are being reconfigured in a myriad of different ways to such a degree that their regulation through policies might be difficult, as well as futile during a period when development and change is so rapid. We have called this development ambivalent research advancement in that it signals changes within the relationship between research and treatment in such a way as to elicit tensions between existing policies and new practices. This ambivalence also gives rise to new configurations and distributions of responsibility and authority, which are not clear in all circumstances. Hoeyer (2008) has pointed out that traditionally the ambiguities related to biobanking have sought to be mitigated through the practice of informed consent, which he argues, is not a good medium through which rights, responsibilities and obligations can be managed. We would agree with this assertion and like to suggest that institutions (hospitals, insurance companies) and state organisations begin to discuss whether the dichotomy between research and treatment within biobanking is any longer a useful distinction.

A number of recent commentators have suggested that biobanks begin to develop new ways of dealing with findings, which may have significance to sample donors (Wolf et al., 2012). This line of thought has been derived from previous experiences of developing ways of warning at-risk relatives of a serious or life-threatening condition (Offit et al., 2004; Tupasela, 2012). Although this could be arguably viewed as setting policies and guidelines for the return of incidental findings and individual research results, we suggest that it highlights the problematic notion of therapeutic misconception in the first place. In many cases, it does not recognize sufficiently the changing relation and role played by research subjects and patients within new configurations of biobanks and healthcare systems. We have furthermore suggested that this tension between policies and practice can be called ambivalent research advancement because the roles and duties, which have traditionally been ascribed to patients and their privacy, are becoming increasingly contested and problematic. This line of argumentation also follows on from the recognition that research subjects and patients can have a broad range of different expectations related to participation in research, as well as medical treatment.

Following Dressers' (2002) idea where research may indeed be contributing to notions of therapeutic misconception, we would like to emphasize that within recent biobanking developments the concept of therapeutic misconception is increasingly problematic. This is due to the ways in which biobanking research is increasingly envisioned where the border between research and treatment is in fact blurry and deconstructed in many ways. We suggest, therefore, that instead of discussing issues of IF and IRR in relation to therapeutic misconception we begin to understand the myriad ways in which biobanking practices are constructing novel relationships between research and treatment. Through this understanding we can begin to develop a new theoretical understanding of the changing role of the research subject, the patient and the researchtreatment system into which they are embedded. 


\section{Acknowledgements}

This research was made possible by funding from the Finnish funding agency for innovation (Tekes) under the research project Patients, Business and the State (2013 - 2014). Tupasela would also like to acknowledge the support of the project Global genes, local concerns, which has been funded by the University of Copenhagen 2016 funds.

\section{References}

American College of Medical Genetics (2013) ACMG Recommendations For Reporting Of Incidental Findings In Clinical Exome And Genome Sequencing. Genetics in Medicine 15(7): 565-574.

Appelbaum PS, Roth LH \& Lidz C (1982) The Therapeutic Misconception: Informed Consent in Psychiatric Research. International Journal of Law and Psychiatry 5:319-329.

Aromaa A, Launis V \& Lötjonen S (2002) DNA-näytteet epidemiologisissa tutkimuksissa. [DNA samples in epidemiological research]. DNA ja Epidemiologia -työryhmä, Helsinki:TUKIJA/ETENE.

Barbour V (2003) UK Biobank: A Project in Search of a Protocol? The Lancet 361: 1734-38.

Bledsoe MJ, Wright Clayton E, McGuire AL, Grizzle, WE, O'Rourke, PP \& Zeps N (2013) Return Of Research Results From Genomic Biobanks: Cost Matters. Genetics In Medicine 15: 103-105.

Burke W, Evans B \& Jarvik GP (2014) Return of Results: Ethical and Legal Distinctions Between Research and Clinical Care. American Journal of Medical Genetics 166C: 105-111.

Cambon-Thomsen A, Rial-Sebbag E \& Knoppers BM (2007) Trends in Ethical and Legal Frameworks for the use of Human Biobanks. European Respiratory Journal 30(2): 373-382.

Curnutte M \& Testa G (2012) Consuming Genomes: Scientific And Social Innovation In Direct-To-Consumer Genetic Testing. New Genetics and Society 31(2): 159-181.

Deschênes M, Cardinal G, Knoppers BM \& Glass KC (2001) Human Genetic Research, DNA Banking and Consent: a Question of 'Form'? Clinical Genetics 59: 221-239.

Douglas C, van El C, Radstake M, van Teeffelen S \& Cornel MC (2012) The Politics of Representation in the Governance of Emergent 'Secondary Use' Biobanks: The Case of Dried Blood Spot Cards in the Netherlands. Studies in Ethics, Law and Technology 6(1): art.4.

Dresser R (2002) The Ubiquity and Utility of the Therapeutic Misconception. Social Philosophy and Policy 19(2): 271-294.

Eisemann E \& Haga SB (1999) Handbook on Human Tissue Sources - A National Resource of Human Tissue Samples. RAND Monograph Report. Santa Monica: RAND.

Eriksson S (2004) Should Results From Genetic Research Be Returned To Research Subjects And Their Biological Relatives? TRAMES 8: 46-62.

European Commission (2013) Commission Staff Working Document - Use Of '-Omics' Technologies In The Development Of Personalised Medicine. Brussels: European Commission.

EU Workshop (2003) Biobanks for Health - Optimising the Use of European Biobanks and Health Registries for Research Relevant to Public Health and Combating Disease. Report and recommendations from an EU workshop held at Voksenåsen Hotel, Oslo 28-31 January.

Fernandez CV, Kodish E \& Weijer C (2003) Informing Study Participants of Research Results: an ethical Imperative. IRB: a Review of Human Subjects Research 25(3): 12-19.

Frank L (2000) When an Entire Country is a Cohort. Science 287(5462): 2398-2399. 
Green, RC, Berg JS, Grody WW, Kalia SS, Korf BR, Martin CL, McGuire AL, Nussbaum RL, O'Daniel JM, Ormond KE, Rehm HL, Watson MS, Williams MS \& Biesecker LG; American College of Medical Genetics and Genomics (2013) ACMG Recommendation for Reporting of Incidental Findings in Clinical Exome and Genome Sequencing. Genetics in Medicine 15(7): 565-574.

Halverson CME \& Friedman Ross L (2012) Incidental Findings Of Therapeutic Misconception In BiobankBased Research. Genetics in Medicine 14(6): 611-615.

Hansson MG, Dillner J, Bartram CR, Carlsson J \& Helgesson G (2006) Should Donors be Allowed to Give Broad Consent to Future Biobank Research? Lancet Oncology 7: 266-269.

Henderson GE, Churchill LR, Davis AM, Easter ME, Grady C, Joffe S, Kass N, King NMP, Lidz CW, Miller FG, Nelson DK, Peppercorn J, Bluestone Rothschild B, Sankar P, Wilfond BS \& Zimmer CR (2007) Clinical Trials and Medical Care: Defining the Therapeutic Misconception. PLoS Medicine 4(11): 1735-1738.

Hewitt R (2011) Biobanking: The Foundation of Personalised Medicine. Current Opinion in Oncology 12:112119.

Hoeyer K (2003) 'Science is Really Needed - That's All I Know'. Informed Consent and the Non-Verbal Practies of Collecting Blood for Genetic Research in Nothern Sweden. New Genetics and Society 22(3): 229-244.

Hoeyer K (2008) The Ethics of Research Biobanking: A Critical Review of the Literature. Biotechnology and Genetic Engineering Reviews 25(1): 429-452.

Hoeyer K \& Hogle L (2014) Informed Consent: The Politics of Intent and Practice in Medical Research Ethics. Annual Review of Anthropology 43: 347-362.

McGowan ML, Fishmanand, JR \& Lambrix MA (2010) Personal Genomics And Individual Identities: Motivations And Moral Imperatives Of Early Users. New Genetics And Society 29(3): 261-290.

Miller F, Giacomini M, Ahern C, Rober, J \& de Laat S. (2008) When Research Seems Like Clinical Care: a Qualitative Study of the Communication of Individual Cancer Genetic Research Results. BMC Medical Ethics 9(4).

National Bioethics Advisory Commission (2001) Ethical and Policy Issues in International Research: Clinical Trials in developing Countries. Available at: https://bioethicsarchive.georgetown.edu/nbac/pubs.html (accessed 8.4.2016).

Nobile H, Vermeulen E, Thys K, Bergmann M \& Borry P (2013) Why Do Participants Enroll In Population Biobank Studies? A Systematic Literature Review. Expert Review of Molecular Diagnostics 13: 35-47.

Nørgaard-Pedersen B \& Hougaard DM (2007) Storage Policies And Use Of The Danish Newborn Screening Biobank. Journal of Inherited Metabolic Diseases 30: 530-536

OECD (2001) Biological Resource Centres: Underpinning the Future of Life Sciences and Biotechnology. OECD, Paris.

Offit K, Groeger E, Turner S, Wadsworth E \& Weiser M (2004) The 'Duty To Warn' A Patient's Family Members About Hereditary Disease Risk. Journal of American Medical Association 292: 1469-1473.

Pellegrini I, Chabannon C, Mancini J, Viret F, Vey N \& Julian-Reynier C (2014) Contributing to research via biobanks: what it means to cancer patients. Health Expectations 17(4):523-33.

Prainsack B (2014) The Powers of Participatory Medicine. PLOS Biology 12(4): e1001837.

Riegman PH, Morente MM, Betsou F, de Blasio P \& Geary P; Marble Arch International Working Group on Biobanking for Biomedical Research (2008) Biobanking for Better Healthcare. Molecular Oncology 2: 213-222.

Simeon-Dubach D \& Watson P (2014) Biobanking 3.0: Evidence based and Customer Focused Biobanking. Clinical Biochemistry 47: 300-308.

Skolbekken J-A, Øystein Ursin L, Solberg B, Christensen E \& Ytterhus B (2005) Not Worth The Paper It's Written On? Informed Consent And Biobank Research In A Norwegian Context. Critical Public Health 15(4): 335-347. 
Smith M \& Aufox S (2013) Biobanking: The Melding of Research with Clinical Care. Current Genetics Medicine Reports 1(2): 122-128.

Snell K, Starkbaum J, Lauß G, Vermeer A \& Helén I (2012) From Protection of Privacy to Control of Data Streams: A Focus Group Study on Biobanks in the Information Society. Public Health Genomics, 15(5):293302.

Soini S (2013) Finland On A Road Towards A Modern Legal Biobanking Infrastructure. European Journal of Health Law 3: 289-94.

Strong DM (2000) The US Navy Tissue Bank: 50 Years on the Cutting Edge. Cell and Tissue Banking 1: 9-16.

Tupasela A (2004) Ihmiskudoksen lääketieteellinen käyttö Suomessa [The medical use of human tissue in Finland]. Suomen lääkärilehti 59(43)4162-4164.

Tupasela A (2006) When Legal Worlds Collide: From Research to Treatment in Hereditary Cancer Prevention. European Journal of Cancer Care 15(3): 257-266.

Tupasela A (2010) Introduction: Consumer Medicine - From Passive Patients to Active Consumers. In: Tupasela A (ed) Consumer Medicine. TemaNord 530. Nordic Council of Ministers: Copenhagen, 13-24.

Tupasela A (2012) Governing Hereditary Disease in the Age of Autonomy. In: Vermeulen N, Tamminen S \& Webster A (eds) Bio-objects: Life in the 21st Century. Ashgate: Surrey, 103-116.

Tupasela A (2015) Tensions Between Policy and Practice in Finnish Biobank Legislation. Biopreservation and Biobanking 13(5): 379-381.

Tupasela A \& Liede S (2016) State Responsibility And Accountability In Managing Big Data In Biobank Research - Tensions And Challenges In The Right Of Access To Data. In: Mittelstadt B \& Floridi L (eds) The Ethics of Biomedical Big Data. Oxford University Publishing: Oxford. Forthcoming, 257-275.

Wadmann S \& Hoeyer K (2014) Beyond the Therapeutic Misconception': Research, Care and Moral Friction. BioSocieties 9 (1): 3-23.

Wallace HM (2005) The Development of UK Biobank: Excluding Scientific Controversy from Ethical Debate. Critical Public Health 15(4): 323-333.

Wallace SE \& Kent A (2011) Population Biobanks And Returning Individual Research Results: Mission Impossible Or New Directions? Human Genetics 130(3): 393-401.

Wilson GD, D'Angelo K, Pruetz BL, Geddes TJ, Larson DM \& Akervall J (2014) The Challenge of Sustaining a Hospital-based Biobank and Core Molecular Laboratory: The Beaumont Experience. Biopreservation and Biobanking 12(5): 306-311.

Wolf SM, Crock BN, Van Ness B, Lawrenz F, Kahn JP, Beskow LM, Cho MK, Christman MF, Green RC, Hall R, Illes J, Keane M, Knoppers BM, Koenig BA, Kohane IS, Leroy B, Maschke KJ, McGeveran W, Ossorio P, Parker LS, Petersen GM, Richardson HS, Scott JA, Terry SF, Wilfond BS \& Wolf WA (2012) Managing Incidental Findings And Research Results In Genomic Research Involving Biobanks And Archived Data Sets. Genetics in Medicine 14(4): 361-384.

Yuille M, van Ommen GJ, Bréchot C, Cambon-Thomsen A, Dagher G, Landegren U, Litton JE, Pasterk M, Peltonen L, Taussig M, Wichmann HE \& Zatloukal K (2008) Biobanking for Europe. Briefings in Bioinformatics 9(1): 14-24.

Zawati MH \& Knoppers BM (2012) International Normative Perspectives on the Return of Individual Research Results and Incidental Findings in Genomic Biobanks. Genetics in Medicine 14(4): 484-489.

\section{Notes}

1 See www.auriabiopankki.fi for further information. 